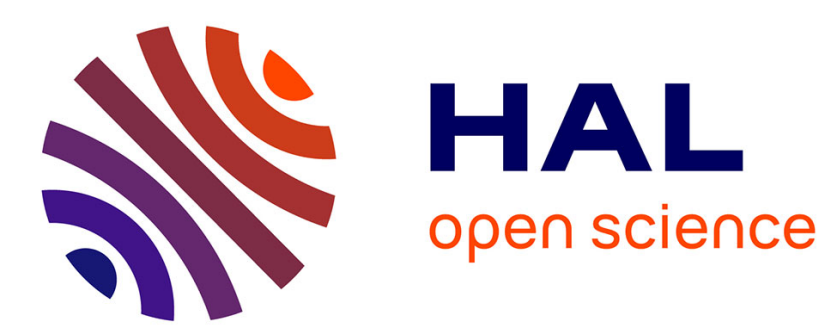

\title{
The Cosmophone: Toward a Sensuous Insight into Hidden Reality
}

C. Vallee

\section{To cite this version:}

C. Vallee. The Cosmophone: Toward a Sensuous Insight into Hidden Reality. Leonardo, 2002, 35, pp.129-129. in2p3-00011770

\section{HAL Id: in2p3-00011770 \\ https://hal.in2p3.fr/in2p3-00011770}

Submitted on 8 Jul 2002

HAL is a multi-disciplinary open access archive for the deposit and dissemination of scientific research documents, whether they are published or not. The documents may come from teaching and research institutions in France or abroad, or from public or private research centers.
L'archive ouverte pluridisciplinaire HAL, est destinée au dépôt et à la diffusion de documents scientifiques de niveau recherche, publiés ou non, émanant des établissements d'enseignement et de recherche français ou étrangers, des laboratoires publics ou privés. 
Article paru dans la revue Leonardo, Vol. $35 \mathrm{~N}^{\mathrm{o}} 2$ (2002)

Journal of the International Society for the Arts, Sciences and Technology, The MIT Press.

http://mitpress.mit.edu/Leonardo

THE COSMOPHONE: TOWARDS A SENSUOUS INSIGHT INTO HIDDEN REALITY

\author{
Claude Vallée \\ Centre de Physique des Particules de Marseille \\ IN2P3-CNRS \\ 163 Avenue de Luminy - Case 907 \\ F-13288 Marseille cedex 09 France \\ e-mail: vallee@cppm.in2p3.fr \\ web site: http://cosmophone.in2p3.fr
}

Art and science are both driven by a quest for truth. Their ways are different: the strength of emotion on the one hand, the confrontation of a concept with experiment on the other. But they may join each other in the emotion which can result from a direct contact with a hidden unexpected physical phenomenon.

The cosmophone ${ }^{1}$ is a tentative step in this direction. The installation magnifies the cosmic radiation of protons which originate from within our galaxy and constantly bombard the Earth. When impinging upon the atmosphere, they create showers of secondary particles. The most penetrating of these, called "muons", reach sea level. These muons traverse our bodies at a high rate without leaving any sensorial hint of their passage.

The cosmophone is designed to make the flux and properties of cosmic muons directly perceptible within a three-dimensional space (Fig. 1). This is done by coupling a set of elementary particle detectors to an array of loudspeakers by a real time data acquisition and numerical sound synthesis system. Muon detection uses standard techniques of experimental particle physics. The pieces of information received from the detectors instantaneously trigger the emission of sounds which depend on the parameters of the detected particles. For example, the trajectory and speed of a muon are characterized by a sound which is moved in space from the muon's entry point in the cosmophone down to its exit point, while shifting the sound's frequency as would occur with a real moving sound source (Doppler effect). Low rate phenomena, like the radiation of showers of electron/anti-electron pairs from muons, are rendered by special sound effects. They provide an additional source of randomness and variety in a given listening sequence.

In the cosmophone, the choice of sound as medium is essential for several reasons. First of all, sound is transmitted as a mechanical vibration. This makes hearing a kind of long range touch which provides a direct contact with the distant phenomenon. Secondly, recent techniques of numerical sound synthesis allow a flexible real-time three-

\footnotetext{
${ }^{1}$ The cosmophone has been developed together with David Calvet, from the Centre de Physique des Particules de Marseille, and Richard Kronland and Thierry Voinier, from the Laboratoire de Mécanique et d'Acoustique, Marseille, France. A twenty square meter cosmophone can be visited in the permanent exhibition of the Cité des Sciences et de l'Industrie, Paris, France. The cosmophone is patented by the Centre National de la Recherche Scientifique, France.
} 
dimensional imaging of particle properties. Such an environmental restitution is essential to the emotional impact of the physics phenomenon. Thanks to the moderate ability of the ear to locate sound sources, this is possible with a rather coarse sampling of space with detectors and loudspeakers. Sound synthesis also gives a large freedom in the choice of sound effects. These could even develop into a musical composition driven by the random fluctuations of cosmic phenomena. Finally, sound imaging allows to completely hide the technology which creates it, favouring a focus on the physics phenomenon itself. An ideal cosmophone would be a place which would make every entering visitor suddenly sensitive to a new face of the universe (cosmic radiation) as if by magic.

The principles which guided the design of the cosmophone could be applied to many other physical phenomena. I believe that there exists a whole domain to develop in order to extract beauty and emotion from the hidden complexity of nature.

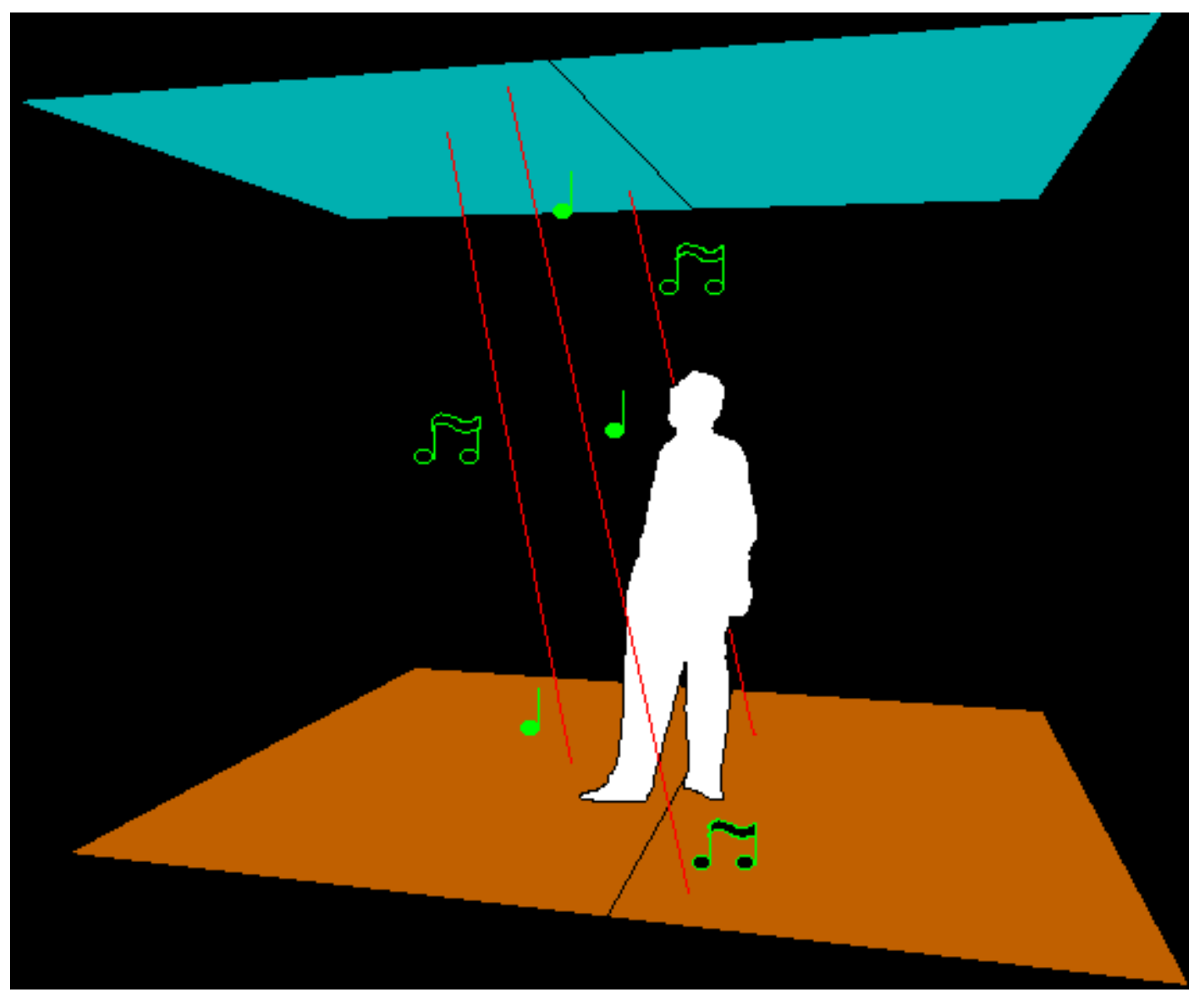

Fig 1: The cosmophone materializes in sounds a hidden part of reality: cosmic radiation. 